\begin{abstract}
to appear 1999 in Proceedings of the 25th Linguistic Colloquium on Romance Languages, ed. by

M. Authier, B.Bullock, and L.Reed, John Benjamnins'
\end{abstract}

\title{
Lexical conservatism in French adjectival liaison
}

\author{
Donca Steriade \\ UCLA
}

\section{Introduction}

The object of this study are the phonological mechanisms that signal lexical relations. To indicate that a form is closely related to another, in semantic content or morphosyntactic function, speakers employ similarities of phonological shape. For instance a nonce word like aspiratory ["œspIr" Ætori] will be interpreted as related to áspirate, not to aspíre; and conversely ['s"paIr' Ætori] will convey a lexical connection to aspíre, not áspirate. Phonological similarity to a known form is used to guide the interpretation of the unfamiliar one.

There is now growing consensus on the nature of the phonological mechanisms that have this signalling function. First, a number of phonologists have argued that it is the similarity between surface forms that is being manipulated (Benua 1995, Burzio 1994, Flemming 1995, Kenstowicz 1996, McCarthy and Prince 1995, Steriade 1996). Second, the relevant surface identity conditions are ranked and violable preferences, in the OT sense (cf. Prince and Smolensky 1993, and subsequent literature). Thus it is preferable for the stem of the -atory adjective based on aspirate to be identical to a surface realization of aspirate, but this preference may be overridden by conflicting considerations.

The standard facts of French adjectival liaison (Tranel 1981) pose a challenge to our understanding of the process of signalling lexical relations through phonological similarity. The preposed adjectives in (1) are masculine, like their head nouns, but they look strictly like citation feminine forms.

(1) a. nouvel an [nuvEl a)] 'new year'

masc. citation [nuvo]; fem. [nuvEl]

b. bon endroit [bOn A)d Âwa] 'right place' masc. citation [bO)]; fem. [bOn] 


\section{c. petit enfant [p' tit A)fA)] 'little child' masc. citation [ $\mathrm{p}^{\prime}$ ti]; fem. [ $\mathrm{p}^{\prime}$ tit]}

I argue that the adjectives in (1) are syntactically masculine, not feminine or gender neutral. Their failure to resemble masculine citation forms and their misleading similarity to the feminines stem from the conflict between conditions of phonological well formedness and conditions of lexical conservatism. Lexical conservatism is the new proposal here: it is a class of grammatical conditions taking the form in (2) and promoting the use of pre-existing, familiar expressions, or parts or properties of such expressions. They penalize the use of unprecedented, linguistically innovative expressions.

(2) Property $\mathrm{P}$ of a novel form of morpheme $\mu$ has a precedent in property $\mathrm{P}$ of a listed form of $\mu$.

Although lexical conservatism has effects throughout the grammar, the variety of lexical conservatism investigated here involves only avoidance of phonological innovation.

\section{Lexical conservatism in English Level 2 phonology}

The effect of lexical conservatism conditions and the formalism they require can be initially justified with data from English Level 2 phonology. This data will allow us to place the liaison facts in (1) in a broader context. There exists a class of English affixes which can give rise, variously, to Level 1 and Level 2 formations (Aronoff 1976). Level 2 forms are defined by the invariance of stresses in the stem, relative to the pronunciation of the stem in isolation: for instance invalidism is recognized as a Level 2 form because its stem is identical, stresswise, to that of invalid. The accentual resemblance between base and derivative is obtained in this case the cost of metrical deviance: invalidism contains a string of 4 stressless syllable, more than normally tolerated in English.

The same suffix -ism can generate accentually modified, Level 1 forms, as in bureáucratism. The stress of this form differs from that of its base, búreaucrat. Thus -ism can apparently generate both Level 1 and Level 2 formations. Similarly -able generates mostly Level 2 forms, as in admínistrable (on admínister; not *adminístrable), párodiable (on párody, *paródiable) but occasionally it does generate apparent Level 1 forms like demónstrable, with shifted stress relative to the démonstrate; or remédiable, which differs similarly from rémedy.

This ability of certain affixes to generate either Level 1 or Level 2 formations is in fact just a reflex of lexical conservatism. The analysis I suggest goes as follows: 
to optimally satisfy conditions of metrical well formedness, it is sometimes necessary for the stress of the affixed word to be modified relative to the stress of its base. For instance, bureáucratism is better stressed than the alternatives búreaucràtìsm, or bùreaucrátìsm because it avoids stress clash. Similarly, demónstrable is better stressed than démonstrable because it reduces the length of the string separating the last stress from the right edge of the word, the length of the lapsed string. The considerations of Lapse and Clash avoidance motivate then these stress changes. However, stress changes occur with suffixes like -ism and able only if the accentual pattern desired for the derivative has a counterpart in some other listed allomorph of the stem. It must not be an unprecedented stress profile within the relevant lexical paradigm. This is where lexical conservatism comes in. For instance: demónstrable differs from démonstrate but displays the stress profile already present in demónstrative; buréaucratism displays the stress familiar from the form bureáucracy. When the base word has only one stress option, neither-ism nor -able will induce stress changes. Thus, the noun invalid, has only one form: no variant such as inválid- exists independently in this lexical entry ${ }^{1}$. For this reason, it is not possible to improve the stress of invalidism by shifting stress (*inválidism). Similarly, among the forms that can undergo -able affixation, admínister, unlike démonstrate, has only one stress option: there is no independently established form such as *adminístrative to license a shift in stress in the -able form.

Our conclusion then is that the "Level 2" forms - those where stress remains in the position of the base word - are based on impoverished paradigms, in which only one accentual profile is independently attested. The "Level 1" forms on the other hand, with shifted stress, are based on accentually richer paradigms, that provide a model for the stress profile desired in the derivative. The level difference is entirely predictable from the paradigmatic structure. The correlation between the possibility of stress changes and paradigm structure is more general within the class of English learned suffixes and in English phonology in general (Steriade 1998).

Note now an interesting property of the "Level 1" formations: they are splitbase formations, in that they have not one but two or more bases. This means that the properties of the derivative are determined by consulting several forms from a given paradigm. For instance, the semantics of autómatism are closely related to those of àutomátic, but the stress of this word comes from autómaton. Similarly, the -able forms require a transitive verb as their base, hence they are based, in a morphosyntactic sense, on verbs like démonstrate or rémedy. But the stress comes from non-verbal demónstrative, remédial. In other words, these forms are

1 The verb inválidate is semantically unrelated. 
split-base formations: their phonological, syntactic and semantic properties are computed by consulting the entire paradigm of the stem, not a unique base form ${ }^{2}$.

We can summarize the discussion so far as follows: certain phonological preferences induce changes in the phonology of the stem relative to the shape of the morphosyntactic or semantic base word. Such changes take place only if the resulting stress pattern is already attested in some pre-existing form of the stem. This condition, the requirement that a lexical precedent exist for the phonological properties adopted in the derivative, is an instance of lexical conservatism, as anticipated in (2). Lexical conservatism in conjunction with phonological dispreferences (e.g. Lapse and Clash) yields split base effects.

\section{Formalizing lexical conservatism and split base effects}

A number of questions arise regarding the nature of lexical conservatism and the formal conditions that enforce it. The fundamental question is: what counts as a listed form? Also: what is the form of lexical conservatism conditions? What is the range of phonological properties for which conservatism may be required through such conditions? How do lexical conservatism conditions relate to the more familiar correspondence conditions that the recent work has concerned itself with? I outline answers to these questions as suggested by the English Level 2 data and then turn to French liaison facts to demonstrate that the same analytical moves provide an interesting analysis of that case as well.

Lexical conservatism (Lex P) constraints take the form in (3):

(3) Let $T(\mu)$ be the allomorph of $\mu$ appearing in a form under evaluation.

Let $\mathrm{L}(\mu)$ be a listed allomorph of $\mu$. Let $\mathrm{P}$ be a phonological property.

$\mathrm{T}(\mu)$ is characterized by $\mathrm{P}$ only if some $\mathrm{L}(\mu)$ is characterized by $\mathrm{P}$.

An instance of LexP is the condition in (4):

\section{(4) Lex [ \pm stress $]$ :}

Let $\sigma(T)$ be a syllable in the target form $T(\mu)$ of morpheme $\mu$. There is a listed allomorph of $\mu, \mathrm{L}(\mu)$, such that for any $\sigma(\mathrm{T}), \sigma(\mathrm{T})$ has a correspondent $\sigma(\mathrm{L})$ in $\mathrm{L}(\mu)$ and $\sigma(\mathrm{T})$ is [ $\alpha$ stressed] only if $\sigma(\mathrm{L})$ is [ $\alpha$ stressed].

Lex [ \pm stress] evaluates candidates by searching the lexicon for any listed allomorph of the relevant morpheme that possesses accentually identical syllables corresponding to the syllables of a given candidate. In this way it verifies that the

\footnotetext{
2 The existence of the split-base effect has been independently discovered by Burzio (1997).
} 
stress profile adopted by the candidate has a listed precedent. Sample evaluations appear below:

(5) Lex [ \pm stress] evaluations

(a) listed allomorphs: include rémedy, remédi- (al)

\begin{tabular}{|l|c|}
\hline & Lex [ \pm stress] \\
\hline i. remédi-able & (cf. remédi-al) \\
\hline ii. rémedi-able & (cf. rémedy) \\
\hline
\end{tabular}

(b) listed allomorphs: include párody, not *paródial

\begin{tabular}{|l|c|}
\hline & Lex $[ \pm$ stress $]$ \\
\hline i. párodi-able & (cf. párody) \\
\hline ii. * paródi-able & *No matching $\mathrm{L}(\mu)$ ! \\
\hline
\end{tabular}

Given Lex [ \pm stress], it is possible to derive some of the data noted earlier, by assuming that a specific variety of Lapse avoidance (*Lapse $\sigma \sigma \sigma$ : the condition penalizing final strings of three stressless syllables) is outranked by Lex [ \pm stress]. Under this ranking, *Lapse $\sigma \sigma \sigma$ can be satisfied only in paradigms that are rich enough to offer a listed allomorph with the appropriate stress profile.

(6) (a) listed allomorphs: include rémedy, remédi- (al)

\begin{tabular}{|l|l|l|}
\hline & Lex [ \pm stress] & $*$ Lapse $\sigma \sigma \sigma$ \\
\hline i. + remédi- able & & \\
\hline ii. rémedi- able & & $* !$ \\
\hline
\end{tabular}

(b) listed allomorphs: include párody, not paródial

\begin{tabular}{|l|l|l|}
\hline & & $*$ Lapse $\sigma \sigma \sigma$ \\
\hline i. + párodi- able & & \\
\hline ii. paródi-able & $* !$ & \\
\hline
\end{tabular}

We consider now a different question: what is the range of properties for which lexical conservatism may be mandated? Are these strictly local properties such as individual features or the feature composition of selected segments? Or global properties such as the overall structure and feature composition of a larger selected substring? This is a fundamental question for all theories of correspondence, whether or not lexical conservatism plays a role in them. A key element in the analysis of French liaison will be that the global structure and composition of lexical landmarks such as the stressed syllable or the word margins 
play a fundamental role in correspondence, exactly as they do in lexical access (Cutler 1989, Marslen Wilson 1989).

The English data also sheds some light on this. In the course of verifying the analysis sketched above against a larger corpus of affixed forms I came across able forms like intúitable, contríbutable, domésticable, which appear exceptional: given paradigms such as \{intúit, intuítion\}, \{contríbute, còntribútion \}, \{domésticàte, dòmestícity\}, our analysis predicts *intuítable, *còntribútable, *dòmestícable or *intu[I!S]able, *còn-tribú[S]able, *dòmestí[s]able, with stress contour and segmentals taken from the nominal allomorph. The ungrammaticality of *intu[I!S]able etc. suggests that the last stem consonant must come from the form perceived as the morphosyntactic or semantic base of the derivative: since the -able form requires a verb as its morphosyntactic base, the final consonant in the -able stem must be identical to the final consonant of the verbal stem ${ }^{3}$. This requirement excludes *intu[I!S]able. The corresponding condition appears in (7), and is followed by a sample evaluation.

(7) Lex (C], lexcat): If $T(\mu)$ and some listed allomorph of $\mu, L(\mu)$, have the same lexical category, then, if there is a final consonant $\mathrm{C}$ in $\mathrm{T}(\mu), \mathrm{C}$ has a correspondent $C^{\prime}$ in $\mathrm{L}(\mu)$ and is featurally identical to $C^{\prime}$.

Listed allomorphs: include [Intu!It] (Vb.) [I ntuI!S' n] (N)

\begin{tabular}{|l|c|}
\hline & Lex (C], lexcat) \\
\hline i. intu[I!t]able & (cf. [Intu!It]) \\
\hline ii. intú[It]able & (cf. [Intu!It]) \\
\hline iii. intu[I!S]able & *No matching L $(\mu) !$ \\
\hline
\end{tabular}

The assumption behind conditions like (7) is that the presence in the target form of certain syntactic or semantic features is signalled through phonological similarity to some form of the same morpheme which is known to possess the required semantic or syntactic features. The general form of such conditions (which I refer to as Lex PM) is given below:

\footnotetext{
${ }^{3}$ Recall also the form buréaucratism, with [t] from bureaucrat but stress from bureáucracy. We don't say bureáucra[s]ism. presumably because the -ism form normally selects a noun denoting the qualities of individuals, not abstract or collective nouns like bureaucracy. So bureaucrat is the semantic base of bureáucratism and in virtue of this, the last consonant of bureaucrat must be found in the stem of the corresponding -ism form.
} 
(8) Let $\mathrm{T}(\mu)$ be the allomorph of $\mu$ in a form under evaluation.Let $\mathrm{M}$ be a morphosyntactic feature required in $\mathrm{T}(\mu)$. Let $\mathrm{L}(\mu)$ be a listed allomorph of $\mu$. Let $\mathrm{P}$ be a phonological property. If $\mathrm{L}(\mu)$ is characterized by $\mathrm{P}$ and $\mathrm{M}$, then

We must now explain why is it impossible to say *dòmes[tI!k]able, *intu[I!t]able, with stress from the non-verbal allomorph and consonantism from the verb. The reason is that the entire contents of the stressed syllable must find a lexical precedent in some listed allomorph: what is disallowed is a stressed syllable whose accentual category is based on one allomorph and whose segmentals come from a distinct one. (Stressless syllables are free from this requirement: the stress category of the presuffixal syllable in buréauc[r't]ism is based on buréauc[r's]y but its consonantism comes from búreauc[AEræt].) The upshot then is that we must admit global correspondence conditions of the form in (9). Lex $\sigma$ ! below supersedes Lex[ \pm stress].

(9) Lex $\sigma$ !: For any stressed syllable $\sigma$ in the target form $T(\mu)$, there is a correspondent $\sigma^{\prime}$ in some listed allomorph, $\mathrm{L}(\mu)$, such that $\sigma^{\prime}$ is stressed and $\sigma$ and $\sigma^{\prime}$ are segmentally identical.

listed allomorphs: [Intu!It] and [I ntuI!S-' n]

\begin{tabular}{|l|l|}
\hline & Lex $\boldsymbol{\sigma}$ ! \\
\hline i. intu[I!t]able & * No matching L $(\mu) !$ \\
\hline ii. intú[It]able & (cf. [Intu!It]) \\
\hline iii. intu[I!S]able & (cf. [IntuI!S-' n]) \\
\hline
\end{tabular}

Since candidate (iii) (intu[I!S]able) violates Lex (C], lexcat), candidate (ii) (intú[It]able) will win under the ranking in (10):

$$
\begin{array}{cr}
\text { Lex } \sigma ! & \quad \text { Lex }(\mathrm{C}], \text { lexcat }) \\
& \quad \mathrm{d} \\
& * \text { Lapse } \sigma \sigma \sigma
\end{array}
$$

One last comment on English before we turn to the French liaison data. What counts a listed form? Normally the answer to this question starts from the a priori assumption that lexical representations are necessarily sparse: a listed form is one stripped of predictable information. The facts examined here point in a different direction. Consider remédiable, the -able form whose stress we have argued is 
based on that of the adjective remédial. The form remédial has the effect of licensing the stress shift in remédiable because it is a listed form: it is known (to those who use remédiable) to be in actual linguistic use and it is known to possess this particular stress pattern. A potential form would not have the same licensing ability: thus *paródial is a potential -al adjective based on parody, and if it did exist it would have this stress. But it does not in fact exist. The paradigmatic difference between rémedy-remédial and párody-*parodial reflects an accidental gap in the English lexicon: speakers' knowledge of this lexical gap explains the difference between remédiable and *paródiable. Note now that while the bare existence of the -al adjective associated with some verbal or nominal paradigm is unpredictable, the stress pattern of the -al adjective is fully predictable: existing - al adjectives invariably follow the rules set forth in Liberman and Prince (1977), Hayes (1981) for weak retractors. And notice finally that it is the predictable stress of remédial that permits the stress shift in the able form. By this reasoning we arrive at the conclusion that the properties allowing a listed form to satisfy Lex P conditions may very well be predictable properties. They are predictable but known. We suggests then that, for purposes of Lex P satisfaction, a listed form is a form sufficiently familiar to the speaker as to inspire the confidence that it is in actual, against potential, linguistic use. Happiness is, in this sense, a listed form, no matter how predictable its properties; a nonce form like randomness, on the other hand, is not. Clearly intuitions of noncehood do exist as distinct from intuitions of grammaticality. We suggest here that the difference between nonce and familiar forms is the relevant one in the analysis of split base effects.

Our discussion so far has suggested the need for conditions of lexical conservatism of the form in (3). We have argued that these conditions may mandate global as against piece-meal identity to some substring within a listed allomorph. I have also suggested that listedness is in part a function the speaker's familiarity with the form, not a function of the predictability of the form's properties. The general picture emerging here is that of an expanded lexicon that includes all actual words generated by the word formation rules, no matter how predictable their properties. This is the view proposed by Halle in his Prolegomena to a Theory of Morphology (1973). This does not exclude the existence of a more abstract and sparse lexicon functioning in parallel, again as Halle envisioned it. But it does suggest that the contents of the richer, familiarity-based lexicon play a critical role in the formation of novel expressions. We now turn to French and explore the interplay of the same ideas in the domain of adjectival liaison.

\section{French liaison analyzed}


Recall the central facts of adjectival liaison illustrated in (1). The interesting question here is why a masculine adjective must look like a feminine when it encurs the risk of hiatus in prenominal position. Part of this question has been addressed by Tranel $(1981,1996)$ and Perlmutter $(1996)$, who point out that the feminine consonant is used in the masculine liaison form to avoid hiatus. If that $\mathrm{C}$ wasn't used, the argument goes, we'd have abutting vowels in forms like *nouveau ami [nuvo ami] 'new friend' etc.

But invoking hiatus yields only part of the answer. Hiatus could also be avoided through vowel loss (e.g. hypothetical *[nuv ami] or *[nuvo mi]) or through consonant insertion $(*[$ nuvo-t-ami] $)$. Given this choice of options, why use the feminine form?

The answer is lexical conservatism. To know an adjective is, in most cases, to know its citation or phrase final forms, feminine and masculine: most adjectives are postnominal in French, and thus occur at the end of an accentual phrase (AP). The prenominal, AP-medial form - and especially the form occurring in potential APinternal hiatus - is considerably less common. If listedness stands for a certain degree of familiarity, then the AP final forms of the masculine and the feminine are listed forms for the bulk of French adjectives. The liason form - which requires the less common prenominal position and a less common class of $\mathrm{V}$ initial head nouns is not necessarily listed. It is not necessarily familiar. It may be listed for certain determiners (such as the possessives, or the demonstrative pronouns) but not in general. We can now explain why the feminine $\mathrm{C}$ is used to avoid hiatus in preference to other means ( $\mathrm{V}$ deletion or $\mathrm{C}$ insertion): the use of the feminine is the only lexically conservative solution to hiatus, the only option that resolves hiatus without resorting to the creation of a phonologically novel form.

Perlmutter (1996) has made a proposal that inspired ours but is distinct from it: his Lexical Sourcing principle states that the candidates to be considered are always lexically listed forms. Lexical Sourcing is an element of grammatical architecture, not a violable constraint, unlike the violable LexP conditions proposed here. Lexical Sourcing yields roughly the correct results for French (although we will see below that it also fails in certain cases) but its general drawback is that it predicts that all phonology will be lexically conservative. Consider the main stress shift in -able forms: ànaly!ze-able, prògrámmable. Note that no listed allomorph of ánaly ze or prógràm has this pattern of main stress. The relevant generalization here is that the suffix -able is lexically conservative only with respect to the distribution of stressed and stressless syllables; -able induces innovative effects with respect to main stress location. Lexical Sourcing does not allow this distinction to be drawn, and since no listed form like ànaly!ze exists it cannot consider this as a candidate for stem realization. We depart then from Perlmutter's 
proposals in two respects: we attribute the effect of Lexical Sourcing to a family of violable constraints, LexP, and we argue for a distinct set of conditions, LexPM, which directly encode semantic and morphosyntactic similarity via phonological similarity, as in (8). The constraint Lex C] in (11) limits the solutions to hiatus to those that are conservative with respect to the choice of final $\mathrm{C}$. Neither $\mathrm{C}$ insertion (*nuvo-t-ami) nor $\mathrm{V}$ deletion (*nuv ami, *nuvo mi) will be conservative solutions in this respect. The tableau in (11.b) establishes the ranking Lex C] > *Hiatus. In an impoverished paradigm like that of joli, which lacks a C- final allomorph, this ranking correctly predicts hiatus.

\section{(11) Lex C]}

There is a listed allomorph of $\mu \mathrm{L}(\mu)$ such that if there is an absolute final $\mathrm{C}$ in the $T(\mu), C$ has an absolute final, featurally identical correspondent $C^{\prime}$ in $L(\mu)$.

(a) listed allomorphs: [nuvo], [nuvEl]

\begin{tabular}{|l|l|l|}
\hline & Lex C] & *Hiatus \\
\hline i. [nuvo] ami & & $* !$ \\
\hline ii. $+[$ nuvEl] ami & & \\
\hline
\end{tabular}

\begin{tabular}{|l|l|l|}
\hline iii. [nuv] ami & $* !$ & \\
\hline ii. [nuvot] ami & $* !$ & \\
\hline
\end{tabular}

(b) listed allomorphs: joli

\begin{tabular}{|l|l|l|}
\hline & Lex C] & *Hiatus \\
\hline i. +joli enfant & & $*$ \\
\hline ii. jolit enfant & $*$ ! No matching $\mathrm{L}(\mu)$ ! & \\
\hline iii. jol enfant & $*$ ! No matching $\mathrm{L}(\mu) !$ & \\
\hline
\end{tabular}

The actual choice of hiatus-blocking $\mathrm{C}$ is a more complex issue, as noted by Morin (1992) and Tranel (1996). There are feminine consonants like the S of

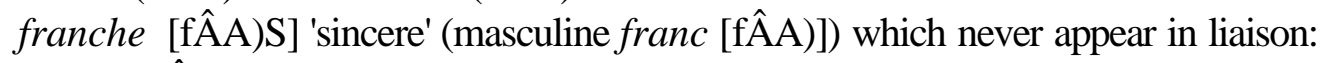

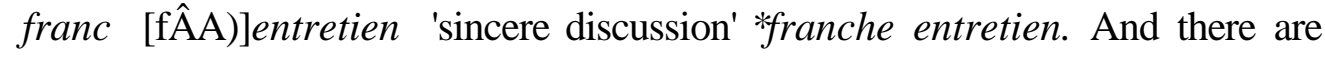
other consonants that undergo changes in liaison relative to the feminine, such as the voicing of [s]: thus the adjective [gÂo] (masc.), [gÂOs] (fem.) is realized as grosse [gÂOs] image 'big image' (a feminine NP) but as gro[z] arbre 'big tree' (masculine NP). The overall generalization is that a limited set of feminine consonants $\{1, \mathrm{r}, \mathrm{n}, \mathrm{z}, \mathrm{t}\}$ are accepted in the adjectival liaison; and that consonants not belonging to this set are either eliminated, or modified as to voicing to gain 
acceptance in the set. So the voicing in gro $[z$ ]arbre is meant to generate $[\mathrm{z}]$, a known liaison consonant. Voicing will not affect other cases $(* v i[v]$ enthusiasme 'lively enthusiasm', for vif enthousiasme or *parfai[d] amour f 'perfect love' for parfai[t] amour). That's because voicing consonants other than [s] will not induce them to belong to this set. Similarly, devoicing of [d] applies occasionally, esp. after a nasal vowel (gran [t] ami 'great friend', secon [t] évènement 'second event') but no general devoicing process is attested in liaison: *joyeu[s] aparté 'merry aside', for joyeu[z] aparté. (cf. citation forms masc. [ZwajP] and fem. [ZwajPz].'merry'). This too follows from the existence of a limited set of acceptable liaison C's, which includes $\{\mathrm{z}, \mathrm{t}\}$ but not $\{\mathrm{s}, \mathrm{d}\}$. Devoicing [d] will yield a member of the liaison set; devoicing [z] will not.

We can ask now: why are $\{\mathrm{z}, \mathrm{t}, \mathrm{n}, \mathrm{r} ; 1\}$ members of the liaison set? What defines this set? The answer is: familiarity with other comparable instances of the liaison alternation. Certain cases of liaison are common and entrenched: this is the case with plural $[\mathrm{z}]$ (beau[z] enfants beautiful children') and the $[\mathrm{t}]$ in obligatorily prenominal determiners like ce/cette (cet ami 'this friend'). Similarly, certain frequent and obligatorily prenominal determiners (mon 'my' ton 'your' son 'his, hers', bon 'good' in the syncategorematic sense) establish the use of [n] as liaison C: [mOln] ami 'my friend', [bOn] ami 'good friend'. Other obligatorily prenominal determiners establish the use of liaison [r]: premier homme [pÂ' mjEÂ Om] 'first man'. In contrast, there is no precedent - in structures of obligatory liaison - for the use of consonants such as $[\mathrm{S}],[\mathrm{j}],[\mathrm{d}],[\mathrm{s}]$ as alternating hiatus buffers. This is due to the extreme rarity of these consonants in the final position of adjectives suited for (or restricted to) prenominal position or in the final position of any other lexical items occurring as the first term in contexts of obligatory liaison. It is for this reason that fran [S] entretien is disallowed. This expression is essentially a nonce formation and the speaker cannot justify the use of [S] as a hiatus buffer in terms of known lexical precedents, i.e. in terms of other cases where the same alternation occurs between $\varnothing$ (in citation) vs. C (in potential AP-internal hiatus). This idea can be faithfully formalized using the LexP format. For reasons of space, however, I will take here the analytical shortcut in (11).

\section{(11) Liaison $\mathbf{C}$}

Let $\mathrm{T}(\mu)$ be the form of $\mu$ under evaluation. Let $\mathrm{C}(\mu)$ be a citation form of $\mu$, whose morphosyntactic features are identical to $T(\mu)$ 's. If $S$ is a consonantal then $\mathrm{S} \quad\{\mathrm{t}, \mathrm{z}, \mathrm{n}, \mathrm{l}, \mathrm{r}\}$

The ranking in (12) will characterize Tranel's and Morin's observations: for [s], a simple voicing modification can yield a known liaison $\mathrm{C}$; on the other hand, for $\mathrm{S}$, 
voicing does not have this result, since [Z], its voiced counterpart, is not in the set of acceptable liaison C's.

(12) Liaison C > * Hiatus >> Ident [voice]

listed allomorphs: [gÂAo], [gÂOs]

\begin{tabular}{|c|c|c|c|}
\hline & Liaison C & *Hiatus & Ident voice \\
\hline 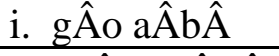 & & $* !$ & \\
\hline ii. $+\mathrm{gA \hat {A }} o z$ aÂÂA & & & $*$ \\
\hline iii. gÂAs aÂÂA & $* !$ & & \\
\hline
\end{tabular}

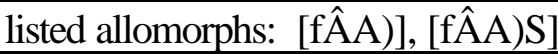

\begin{tabular}{|l|l|l|l|}
\hline & Liaison $\mathrm{C}$ & $*$ Hiatus & Ident voice \\
\hline i. $\left.\mathrm{f} \hat{\mathrm{A} A}) \mathrm{S} \mathrm{A}) \mathrm{t} \hat{\mathrm{A}}^{\prime} \mathrm{tj} \mathrm{E}\right)$ & $* !$ & & \\
\hline ii. $\left.+\mathrm{f} \hat{\mathrm{A}} \mathrm{A}) \mathrm{A}) \mathrm{t} \hat{\mathrm{A}}^{\prime} \mathrm{tj} \mathrm{E}\right)$ & & $*$ & \\
\hline iii. $\left.\mathrm{f} \hat{\mathrm{A} A}) \mathrm{Z} \mathrm{A}) \mathrm{t} \hat{\mathrm{A}}^{\prime} \mathrm{tjE}\right)$ & $* !$ & & $*$ \\
\hline
\end{tabular}

The phrase [fÂA)k A)t $\hat{\mathrm{A}}^{\prime}$ tjE] (cited by Delattre 1966) may indicate that $[\mathrm{k}]$ is a marginal member of the liaison set (perhaps based on the precedent provided by the Marseillaise in [sA)k] impur 'impure blood') or, alternatively, that orthography-based liaison is an option for some speakers.

We have seen so far that Lex P constraints can characterize, in conjunction with others, the basic fact of French liaison - the use of feminine C's as hiatus buffers - as well as restrictions on the set of useable liaison segments.

Recall now that we had motivated a different class of constraints for English: those which use phonological identity to signal morphosyntactic or semantic identity. Recall in particular the constraint Lex (C], lexcat) in (7), which signals that the stem's lexical category via the identity of the stem's last $\mathrm{C}$. The counterpart of this constraint is found in French. Here I draw again on Tranel's and Morin's earlier work, in which they note that adjectives ending in two consonants, one of which appears only in the feminine, employ the masculine citation form in liaison. Thus fort 'strong' (masculine citation [fOÂ]) has the feminine forte [fOÂt] but in the masculine liaison form this $[\mathrm{t}]$ fails to surface: one says [fOÂ] accent. 'strong accent'. So far, nothing in the system we have proposed insures that this will be so. But in fact this is exactly the effect of the French counterpart of the English Lex (C] lexcat) with the minor difference that the final $\mathrm{C}$ is used in French to signal gender, rather than lexical category.

\section{(13) Lex (C], gender)}


If $\mathrm{T}(\mu)$ and some $\mathrm{L}(\mu)$ have the same gender and if a final consonant $\mathrm{C}$ occurs in $\mathrm{T}(\mu)$, then $\mathrm{C}$ has a correspondent $\mathrm{C}^{\prime}$ in $\mathrm{L}(\mu)$ and is featurally identical to $\mathrm{C}^{\prime}$.

The two constraints - English Lex (C], lexcat) and French Lex (C], gender) could be reduced to a single one, which mentions broad morphosyntactic identity, as seen below. This possibility is not pursued here: we will continue to use in the discussion of French the restricted Lex (C], gender).

\section{(14) Lex (C], ms)}

If $T(\mu)$ and some $L(\mu)$ have the same morphosyntactic features and if a final consonant $C$ occurs in $T(\mu)$, then $C$ has a correspondent $C^{\prime}$ in $L(\mu)$ and is featurally identical to $\mathrm{C}^{\prime}$

Lex (C], gender) ranks below *Hiatus (15.a); it has an effect only when *Hiatus is moot, (15.b):

(15) *Hiatus >> Lex (C], gender)

(a) listed allomorphs: $\mathrm{p} \hat{A}^{\prime}$ mje, $\mathrm{p} \hat{\mathrm{A}}^{\prime}$ mjEÂ

\begin{tabular}{|l|l|l|}
\hline & *Hiatus & Lex $(\mathrm{C}]$ gender $)$ \\
\hline i. $+\left[\mathrm{p} \hat{A}^{\prime}\right.$ mjÊÂ $] \mathrm{ami}$ & & $*$ \\
\hline ii. $\left[\mathrm{p} \hat{A}^{\prime} \mathrm{mje}\right] \mathrm{ami}$ & $* !$ & \\
\hline
\end{tabular}


(b) listed allomorphs: fOÂ, fOÂt

\begin{tabular}{|l|l|l|}
\hline & *Hiatus & Lex $(\mathrm{C}]$ gender $)$ \\
\hline i.t [fOÂA $]$ accent & & \\
\hline ii.[fOÂtt $]$ accent & & $* !$ \\
\hline
\end{tabular}

I would like now to analyze an aspect of liaison that is less commonly addressed. The vowels appearing in the accented syllable of feminine and masculine forms of French adjectives are frequently different. Some of the subtler differences are fully predictable from general French phonotactics and give rise to interesting idiolectal differences in the formation of the masculine liaison allomorph. It is this aspect of French liaison that provides the richest evidence for the lexical conservatism analysis and the most striking parallels to the English data analyzed earlier. I review first the range of differences between masculine and feminine vowels, in citation and in liaison. The data comes from Tranel 1981, 1987, Prunet 1987, Fouché 1968 and my own survey of 5 speakers of Standard French:

(16) (a) [+high]/[-high] alternations in oral vowels

\begin{tabular}{|lrr|}
\hline $\begin{array}{l}\text { Masculine } \\
\text { fou }[\mathrm{fu}]\end{array}$ & Feminine & Masc. liaison \\
'crazy' & folle $[\mathrm{fOl}]$ & 'crazy stalk' \\
& & \\
mou $[\mathrm{mu}]$ & molle $[\mathrm{mOl}]$ & [mOl] épis \\
'soft' & & 'soft stalk' \\
\hline
\end{tabular}

(b) [+round]/[-round] and [tense]/[lax] alternations

\begin{tabular}{|c|c|}
\hline Masculine & Feminine \\
\hline nouveau [nuvo] & nouvelle [nuvEl] [nuvEl] $a m i$ \\
\hline 'new' & 'new friend' \\
\hline $\begin{array}{l}\text { vieux }[\mathrm{vjP}] \\
\text { 'old' }\end{array}$ & 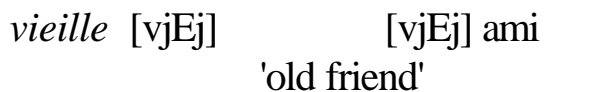 \\
\hline
\end{tabular}




\begin{tabular}{|c|c|c|}
\hline (c) $[+$ nasal $] /[-$ nas & 1] alternations & \\
\hline Masculine & Feminine & Masc. liaison \\
\hline 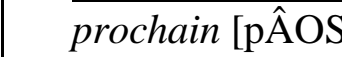 & prochaine & OSEn] [pÂOSEn] [pÂASE)n] \\
\hline arrêt & & \\
\hline 'next' & & op' \\
\hline $\begin{array}{l}\text { soudain [sudE)] } \\
\text { 'sudden' }\end{array}$ & soudaine [sudEn] & $\begin{array}{l}\text { [sudEn] [sudE)n] effet } \\
\text { 'sudden effect' }\end{array}$ \\
\hline $\begin{array}{l}\left.\operatorname{serain}\left[\mathrm{s}^{\prime} \hat{\mathrm{A}} \mathrm{E}\right)\right] \\
\text { 'serene' }\end{array}$ & seraine $\left[\mathrm{s}^{\prime} \mathrm{A} E n\right]$ & $\begin{array}{l}\left.\left[\mathrm{s}^{\prime} \hat{\mathrm{A}} \mathrm{En}\right] \sim\left[\mathrm{s}^{\prime} \hat{\mathrm{A}} \mathrm{E}\right) \mathrm{n}\right] \text { or esprit } \\
\text { 'serene spirit' }\end{array}$ \\
\hline
\end{tabular}

(d) [+high]/[-high] and [tense]/[lax] alternations in nasal rimes

\begin{tabular}{|c|c|}
\hline Masculine & Masc. liaison \\
\hline $\begin{array}{l}\text { commun [kOm")] commune [kOmyn] } \\
\text { 'common' }\end{array}$ & $\begin{array}{l}\text { ??[kOmyn] [kOm")n] accord } \\
\text { 'mutual agreement' }\end{array}$ \\
\hline $\begin{array}{l}\text { divin [divE)] } \\
\text { 'divine' }\end{array}$ & $\begin{array}{l}{[\text { divin }] \sim[\text { divE)n] } \text { archer }} \\
\text { 'divine archer' }\end{array}$ \\
\hline
\end{tabular}

(e) $[$ tense $] /[$ lax $]$ alternations in oral rimes

\begin{tabular}{|c|c|c|}
\hline Masculine & Feminine & Masc. liaison \\
\hline$\overline{\text { premier }\left[\mathrm{p} \hat{\mathrm{A}}^{\prime} \text { mje] }\right.}$ & première $\left[\mathrm{p} \hat{\mathrm{A}}^{\prime}\right.$ mjEÂA] & 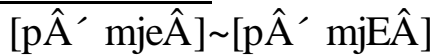 \\
\hline 'first & $a m i$ & 'first friend' \\
\hline parfait $[\mathrm{pa} \hat{\mathrm{A} f e}]^{4}$ & parfaite [paÂfEt] & $\sim[\mathrm{pa} \hat{A} f e t]$ \\
\hline $\begin{array}{l}\text { amour } \\
\quad \text { 'perfect' }\end{array}$ & & 'perfect love' \\
\hline $\begin{array}{l}\text { sot [so] } \\
\text { 'silly, stupid' }\end{array}$ & sotte $[\mathrm{sOt}]$ & $\begin{array}{l}{[\mathrm{sOt}] \sim[\mathrm{sot}] \text { avocat }} \\
\text { 'silly lawyer' }\end{array}$ \\
\hline
\end{tabular}

The vocalic alternations in (16.a) and (16.b) (fou/folle, nouveau/nouvelle ) are of limited generality: one cannot formulate general principles predicting them. All others, however, are predictable, in virtue of the principles in (17):

\footnotetext{
${ }^{4}$ Many speakers still have final [E] here but increasingly this is becoming [e].
} 
(17) Phonological basis for masculine-feminine vowel alternations:

(a) Nasals are disallowed in the same rime as nasal vowels:

[sudEn], [sudE)], * [sudE)n] (alternations in (16.c)).

(b) High nasalized vowels are disallowed:

[divin], [divE)], *[divi)] (cf. high/mid alternations in (16.d))

(c) Word final lax [O] is disallowed: cf. [so] *[sO]

Tense [o] disallowed in most closed syllables: [sOt], ${ }^{*}[\mathrm{sot}]$

Tense [e] disallowed in all closed syllables: [fjEÂ], *[fjê̂]

(cf. tense/lax alternations in (16.e)

With this data as background, we consider certain generalizations about the range of vowel qualities that the liaison masculine can adopt. These will reveal further parallels between the English affixal data and French liaison.

We observe in (16) two ways of forming the liaison masculine. One option is to use the citation feminine form as the masculine anti-hiatus allomorph: e.g. [pÂOSEn] arrêt 'next stop', with [pÂOSEn] strictly identical to the feminine. The alternative is to combine in the liaison rime the feminine consonant with the masculine vowel, that is, the last full vowel of the citation masculine: e.g [pÂOSE)n] arrêt, with [n] from the feminine [pÂOSEn] and [E)] from the citation masculine [pÂOSE)]. All variants recorded above represent instances of these two options. The interest of solutions like [pÂOSE)n] arrêt is that these are split-base expressions: the phonological composition of the liaison form is based simultaneously on the citation feminine and the citation masculine form. The masculine vowel in forms like [pÂOSE)n] arrêt. is employed to signal the gender of the adjective: this is done, via a LexPM condition of the sort examined earlier, by selecting a phonological property - the nuclear quality of accented V - which must be identical to the accented nucleus of a listed form of the appropriate gender. The listed form is, in this case, the citation masculine. The relevant LexPM condition appears below, accompanied by a sample evaluation:

\section{(18) Lex $(V$, gender )}

If $T(\mu)$ and some $L(\mu)$ have the same gender features, then the accented $V$ in $\mathrm{T}(\mu)$ has a correspondent $\mathrm{V}^{\prime}$ in $\mathrm{L}(\mu)$, and is identical featurally and stresswise to $\mathrm{V}^{\prime}$. 
listed allomorphs:

[pÂemje] (masc.) [pÂAemjEÂA ]

\begin{tabular}{|c|c|}
\hline & Lex $\mathrm{V}$ gender \\
\hline i. $\mathrm{p} \hat{\mathrm{A}}^{\prime}$ mje $a m i$ & \\
\hline 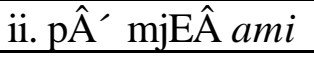 & * \\
\hline 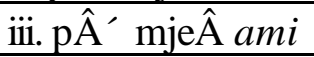 & \\
\hline
\end{tabular}

listed allomorphs:

[pÂOSE)] (masc.) [pÂOSEn]

\begin{tabular}{|l|l|}
\hline & Lex V gender \\
\hline i.pÂOSE) arrêt & \\
\hline ii.pÂOSEn arrêt & $*$ \\
\hline iii.pÂOSE)n arrêt & \\
\hline
\end{tabular}

Candidates (i) above - $\mathbf{p} \hat{A}^{\prime}$ mje] ami and [pÂASE)] arrêt - will be excluded because they violate Hiatus. Therefore candidates (iii) - [p $\hat{\mathrm{A}}^{\prime}$ mjeÂ] $a m i$ and [pÂOSE)n] arrêt - emerge as optimal in systems where Lex(V, gender) is undominated and *Hiatus $>$ Lex (C], gender).

What about phrases like [pÂOSEn] arrêt ? These are so patently deficient at signalling grammatical gender that we must identify the considerations that outrank the expression of gender agreement (i.e. Lex (V, gender)) in order to understand their raison d'être. This consideration is a constraint similar to the English Lex $\sigma$ ' in that both target global identity for some constituent larger than one segment. The French constraint may be viewed as requiring the liaison $\mathrm{VC}$ sequence to be strictly identical to some listed word's rime. Alternatively, the French constraint may simply require global identity between the liaison form and some listed allomorph of the relevant adjective. We adopt this second version. Therefore if the feminine $\mathrm{C}$ is employed in liaison, to block hiatus, the vowel preceding it, along with all other segments, must be identical to that of the feminine, to ensure global identity between the liaison form and some listed allomorph.

\section{(19) Lex P- $\forall$}

There is a $L(\mu)$, such that every segment in $T(\mu)$ has a featurally identical correspondent in $L(\mu)$ and every segment in $L(\mu)$ has a featurally identical

listed allomorphs:

[pÂemje] [pÂemjEÂ ]

\begin{tabular}{|c|c|}
\hline & Lex P- $\forall$ \\
\hline i. $\mathrm{p} \hat{\mathrm{A}}^{\prime}$ mje ami & \\
\hline ii. $\mathrm{p} \hat{A}^{\prime}$ mjEÂ ami & \\
\hline iii. $\mathrm{p} \hat{\mathrm{A}}^{\prime}$ mje $\hat{\mathrm{A}} \mathrm{ami}$ & $*$ \\
\hline
\end{tabular}

listed allomorphs:

\begin{tabular}{|c|c|}
\hline \multicolumn{2}{|c|}{ [pÂASE)] [pÂASEn] } \\
\hline & Lex P- $\forall$ \\
\hline i.pÂASE) arrêt & \\
\hline ii.pÂOSEn arrêt & \\
\hline iii.pÂASE)n arrêt & $*$ \\
\hline
\end{tabular}

Our account of the difference between normative liaison (e.g. $\mathrm{p} \hat{\mathrm{A}}^{\prime}$ mjEÂA $a m i$

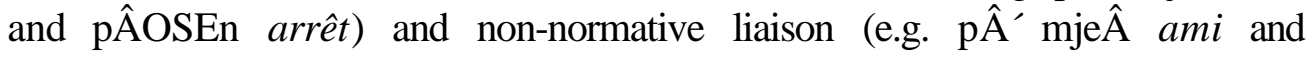


pÂOSE)n arrêt) will rest on the observation that Lex P- $\forall$ (19) is violated by the candidates that emerge as optimal with respect to Lex (V, gender). Our global account of the variation reported in (16) will therefore by a ranking difference between Lex (V, gender) - a Lex PM condition - and Lex P- $\forall$ - a Lex P condition. We illustrate this line of analysis with tableaux that show the effect of changing the ranking between these constraints, while maintaining intact the ranking *Lex $(\mathrm{C}]$ >> Hiatus > Lex (C], gender) established earlier:

(20) (a) Non-normative liaison: [pÂASE)n] arrêt

\begin{tabular}{|l|l|l|}
\hline & Lex (V' gender) & Lex P- $\forall$ \\
\hline i.t [p $\hat{A} O S E) n]$ arrêt & & $*$ \\
\hline ii.[pÂASEn] arrêt & $* !$ & \\
\hline
\end{tabular}

(b) Normative liaison: [pÂOSEn] arrêt

\begin{tabular}{|l|l|l|}
\hline & Lex P- $\forall$ & Lex (V' gender) \\
\hline i.t [p $\hat{A} O S E n]$ arrêt & & $*$ \\
\hline ii.[pÂOSE)n] arrêt & $* !$ & \\
\hline
\end{tabular}

The same ranking variation predicts the difference between normative and nonnormative pairs such as [sot] $a m i$ vs. [sOt] $a m i$, [pr' mjê̂] $a m i$ vs. [pr' mjEÂ] ami, [paÂfet] amour vs. [paÂfEt] amour.

We consider now further implications of this approach. One prediction is that the masculine vowel quality will emerge in both normative and non-normative speech when higher constraints compel violations of Lex P- $\forall$. Thus in gro[z] arbre, the liaison $\mathrm{C}$ is a modified version of the feminine $[\mathrm{s}]$ in grosse [gÂAs]. It is modified to $\mathrm{a}[\mathrm{z}]$ in virtue of rankings discussed earlier in (12). Because this $[\mathrm{z}]$ in gro $[z]$ arbre is distinct from the feminine [s] of [gÂOs], the vowel preceding it is distinct as well: we get $g r[o z]$ arbre, not *[gÂAz] arbre. Similarly, when the plural [z] makes liaison in a masculine NP, the vowel preceding it is the vowel of the citation masculine, not that of the feminine: [sE)gyljez] amis 'odd friends' not [sE)gyljEz] amis (cf. masc. [sE)gylje], fem. [sE)gyljEÂ] 'odd'). In this phrase, the liaison $\mathrm{C}$ is the plural $[\mathrm{z}]$, not the feminine $[\hat{\mathrm{A}}]^{5}$ : consequently, the feminine vowel may not surface and the vowel of the citation masculine singuli[e] apears in liaison. This is true for all classes of speakers, regardless of whether they use, in the singular, the normative [sE)gyljEÂ] ami or non-normative [sE)gylje $\hat{A}]$ ami.

\footnotetext{
${ }^{5}$ The conditions governing the occurence of the plural $[\mathrm{z}]$ are only partly similar to those involved in singular liaison: this $[\mathrm{z}]$ is permitted only before a $\mathrm{V}$-initial word but it is not exclusively used as a hiatus blocker. A partial analysis appears below in (22.b).
} 
Moreover, this is not the effect of purely phonological conditions: there is no phonotactic reason why a phrase like [sE)gyljez] amis cannot be uttered with a lax [E], as [sE)gyljEz] amis . Rather, the Listed Rime generalization, documented in (21), is a direct consequence of the fact that Lex ( $V^{\prime}$, gender) is grammatically relevant for all speakers of French, normative or not. The difference between idiolects involves ranking alone.

(21) The Listed Rime generalization:

The feminine $\mathrm{V}$ appears in masculine liaison only if the feminine $\mathrm{C}$ does.

a. The feminine $\mathrm{C}$ appears in masculine liaison ( normative speech only):

[paÂfEt] amour cf. feminine [paÂfEt], masc. [paÂfe], [paÂfE]

[sE)gyljEÂ] ami cf. feminine [sE)gyliEÂ], masc. [sE)gylje]

[pÂOSEn] arrêt cf. feminine [pÂOSEn], masc. [pÂOSE)]

b. The feminine $\mathrm{C}$ does not appear in liaison (all idiolects):
[gẦz] arbre
cf. masc. [gẦo], fem. [gÂOs]
[sE)gyljez] amis
[pÂOSE)z] arrêts
cf. masc. [sE)gylje], fem. [sE)gyljEÂ]
cf. masc. [pÂASE)]

We illustrate the effect of Lex $\mathrm{V}^{\prime}$ gender in normative dialects by providing the

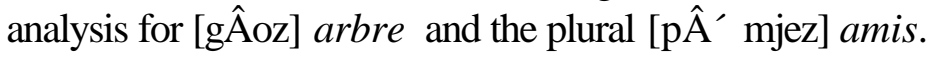

(22) Emergence of gender agreement vowel in normative spech.

Liaison C, MarkPlural > Lex P- $\forall>$ Lex (V', gender)

(a) Listed allomorphs: [gÂAo], [gÂAs]

\begin{tabular}{|l|l|l|l|}
\hline & Liaison C & Lex P- $\forall$ & Lex V', gender \\
\hline i. $[\mathrm{g} \hat{A} \mathrm{Os}]$ arbre & $* !$ & & $*$ \\
\hline ii. $+[\mathrm{gA \hat {A }}]$ arbre & & $*$ & \\
\hline iii. $[\mathrm{gA \hat {AOz }}]$ arbre & & $*$ & $* !$ \\
\hline
\end{tabular}

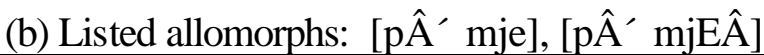

\begin{tabular}{|l|l|l|l|}
\hline & MarkPlural & Lex P- $\forall$ & Lex $\mathrm{V}^{\prime}$, gender \\
\hline i. $\left[\mathrm{p} \hat{\mathrm{A}}^{\prime} \mathrm{mjEz}\right]$ amis & & $*$ & $* !$ \\
\hline ii. $+\left[\mathrm{p} \hat{\mathrm{A}}^{\prime} \mathrm{mjez}\right]$ amis & & $*$ & \\
\hline iii. $\left[\mathrm{p} \hat{A}^{\prime} \mathrm{mjEA}\right]$ amis & $* !$ & & $*$ \\
\hline
\end{tabular}


We observe next that the appearance of tense vowels in the masculine liaison form - as in [gÂtoz] arbre - is strictly determined by correspondence to the masculine citation form. When the masculine citation contains, for any reason, a lax

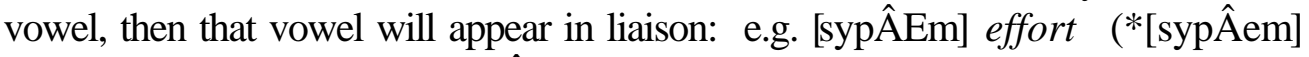
effort ), cf. masc., fem. [sypÂEm] 'supreme'. Similarly, for speakers whose masculine form for 'perfect' is [paÂfE], the liaison form is [paÂfEt] (as in [paÂfEt] amour 'perfect love', *[paÂfet] amour ). This means that there is no general V-tensing process occurring in liaison: rather, the tense vowels in [gÂtoz] arbre, [sE)gyljez] amis or non-normative [sE)gyljê̂A] $a m i$ are the effect of correspondence to the masculine: speakers, in such cases, mark the true gender of the adjective through phonological similarity to a related listed form, the citation masculine. Likewise, the appearance of nasalized vowels in liaison - as in nonnormative [pÂOSE)n] arrêt 'next stop' - is strictly determined by the presence of a nasal vowel in the citation masculine: $[\mathrm{p} \hat{A} \mathrm{OSE})]$. Where the citation masculine contains oral vowels, as in [sypÂEm], the liaison vowel is uniformly oral, for all dialects: [sypÂEm] effort, *[sypÂAE)m] effort . These observations confirm our view that the vowel quality of the liaison rime is used to mark the true syntactic gender of the adjective. The vowel is oral when the citation masculine ends in an oral vowel ([sypÂEm] effort), lax if the citation masculine ends in a lax vowel ([paÂfEt] amour ), nasal (in non-normative speech) if the citation masculine ends in a nasal vowel (non-normative [pÂOSE)n] arrêt ) and tense if the citation masculine ends in a tense vowel (non-normative $[\mathrm{p} \hat{\mathrm{A}}$ ' mjeÂ] amour 'first love').This justifies the adoption of Lex (V', gender) for French and that of LexPM conditions in general.

\section{Extensions}

French (non-normative) liaison phrases like [paÂfet] amour are split-base expressions, and in this they resemble the English derivatives analyzed in the first section of this study. In the French case, one of the two bases is the gender appropriate allomorph - here the citation masculine [paÂfe] - which lends its accented vowel quality to the liaison allomorph and, in this way, signals the gender of the adjective. The other base is the feminine - [paÂfEt] - which lends its $\mathrm{C}$ in order to provide a lexically conservative means of blocking hiatus. The ranking in (20.a), *Hiatus, Lex (V, gender) >> Lex P- $\forall$, Lex C], gender guarantees this mix of properties.

There are however limits to this mix-and-match effect. It is not possible, in any variety of French, to say [nuvol] ami 'new friend' (based on masculine [nuvo] and feminine [nuvEl]) or [ful] espoir 'mad hope' (masculine [fu], feminine [fOI]). In both these cases, the proper way is to use the feminine: [nuvEl] ami , [fOl] espoir. 
Similarly [vjEj] $a m i$ 'old friend, ${ }^{*}[\mathrm{vj} \mathrm{Pj}] a m i$ - with $[\varnothing]$ from the masculine citation [vjP].

Why is it that split-base expressions like [paÂfet] amour, [pÂOSE)n] arrêt, are acceptable to many speakers, while *[nuvol] ami , *[ful] espoir, *[vjPj] ami are acceptable to none? The relevant difference is one of predictability. The tenseness of the accented vowel in [paÂfe]/[paÂfEt] is predictable from the generalization in (17.c): the feminine vowel in paÂfEt] has no choice but to be lax, because it occurs in a closed syllable. Similarly, the oral/nasal quality of the vowel in $[p \hat{A} O S E n] /[p \hat{A O S E})]$ is predictable from the generalization in (17.a): the French rime cannot contain a nasal vowel and a nasal consonant. If the nasal consonant is present, the vowel must be oral. In contrast, the E/o, O/u, E/ø alternations characterizing masculine/feminine pairs like [nuvEl]/[nuvo], [fu]/[fOl], $[\mathrm{vjP}] /[\mathrm{vjEj}]$ are unsupported by any general principles of French phonology. We conjecture further that, all else equal, predictable properties are less salient than unpredictable ones 6 : and therefore that the unpredictable $\mathrm{E} / \mathrm{o}, \mathrm{O} / \mathrm{u}$ and $\mathrm{E} / \varnothing$ differences are more noticeable than the predictable E/e, O/O, E)/En differences. The more noticeable the difference between a liaison rime and an actual listed rime, the more highly ranked the Lex $\mathrm{P}$ constraint penalizing it. In this case, we propose that the relevant Lex $\mathrm{P}$ constraint, Lex P- $\forall$, admits of multiple degrees of strictness, standing in fixed ranking relative to each other. Its strictest version recognizes as equivalent only identical pairs of accented rimes. Thus Lex P- $\forall_{\text {strict }}$ will penalize candidates such as [sot] $a m i$, [pÂOSE)n] arrêt because the final $\mathrm{VC}$ sequence of these adjectives fails to be strictly identical to that of any citation form. A fortiori, this constraint will also penalize *[nuvol] $a m i$, etc., whose perceived difference relative to listed forms is even greater.

A looser version of Lex P- $\forall_{\text {strict }}$, Lex P- $\forall$ loose, will accept as equivalent those pairs of rimes whose elements are differentiated by a property with predictable distribution: thus Lex P- $\forall$ loose will accept [sot] ami (because listed [sOt] is predictably different from [sot]) and [pÂOSE)n] arrêt (because listed [pÂOSEn] is likewise predictably different from [pÂOSE)n]). However, Lex P$\forall$ loose will continue to penalize *[nuvol] ami, *[ful] espoir, *[vjPj] ami because *[nuvol] differs unpredictably, hence more saliently, from both [nuvo] and [nuvEl];

\footnotetext{
${ }^{6}$ For evidence supporting this assumption, cf. Ohala 1981 and Kawasaki 1987, who summarizes as follows the moral of her findings regarding distinctive and non-distinctive denasalization: "whatever a listener expects to hear [...] may be taken for granted and factored out of the phonetic percept constructed for a word." (p.86-87). The assumption made here is that we need to distinguish degrees of perceptual salience, which are in part attributable to predictability, rather than identifying categorically properties that factored in or out in the process of speech perception.
} 
and similarly for the relation between $*[\mathrm{ful}],{ }^{*}[\mathrm{vjPj}]$ and their corresponding citation forms. Being a more modest goal, loose similarity is always more highly ranked than strict similarity, hence the fixed ranking in (23.a). A full account of nonnormative liaison will now be possible: as (23.c-d) show, the difference between acceptable [pÂOSE)n] arrêt and unacceptable [nuvol] ami is captured by the highest ranked constraint, Lex P- $\forall$ loose. In the interest of space, the tableaux in (23) consider only candidates that satisfy *Hiatus. We assume that *Hiatus outranks Lex ( $\mathrm{V}^{\prime}$ gender), in order to explain violations of the latter in [nuvEl] $a m i$ etc.

(23) a. Lex P- $\forall$ loose $>>$ Lex P- $\forall_{\text {strict }}$

b. Non-normative ranking: Lex P- $\forall$ loose $>>$ Lex V' gender $\gg>$ Lex P- $\forall_{\text {strict }}$

c. listed allomorphs: [pÂASE)], [pÂASEn]

\begin{tabular}{|c|c|c|c|}
\hline & Lex P- $\forall$ loose & Lex V', gender & Lex P- $\forall_{\text {strict }}$ \\
\hline i. [pÂASEn] arrêt & & $* !$ & \\
\hline ii. + [pÂASE)n] arrêt & & & * \\
\hline
\end{tabular}

d. listed allomorphs: : listed allomorphs: [nuvo], [nuvEl]

\begin{tabular}{|l|l|l|l|}
\hline & Lex P- $\forall$ loose & Lex V', gender & Lex P- $\forall_{\text {strict }}$ \\
\hline i. $+[$ nuvEl] ami & & $*$ & \\
\hline ii. $[$ nuvol] ami & $* !$ & & $*$ \\
\hline
\end{tabular}

For normative speech, we rank Lex P- $\forall$ loose $>>$ Lex $\mathrm{P}-\forall_{\text {strict }}>>$ Lex (V' gender): this will guarantee both [pÂASEn] arrêt and [nuvEl] $a m i$.

Lexical conservatism also appears to play a role in phrasal sylabification, as it relates to liaison consonants. This is the interpretation we suggest for a number of striking generalizations noted by Tranel (1990), regarding the realization of preposed adjectives when they occur before Right-Dislocated head nouns. Tranel notes that hiatus avoidance is enforced across the prosodic boundary induced by Right Dislocation.

(24) J'en ai un petit, [t]-élephant [pti. \$ te.le.fA)], *[pti. \$ e.le.fA)] 'I have a small one, a he-elephant' ( $\$=$ AP boundary) 


\section{Lexical conservatism in French adjectival liaison}

In general, the liaison $\mathrm{C}$ prefers to syllabify so as to terminate the AP in a form that is identical to the gender-appropriate one: hence the syllabification differences below. 
(25) a.J'en ai un petit, éléphant [pti. \$ te.le.fA)], *[ptit. \$ e.le.fA)] b.J'en ai une petite, éléphante [ptit \$ e.le.fA)t], ${ }^{*}[\mathrm{pti} . \$$ te.le.fA)t] 'I have a small one, a she-elephant.

We attribute this effect to the alignment constraint in (26):

(26) Lex ] AP, gender): The last form of the A-Phrase is identical to a gender appropriate listed allomorph of the relevant morpheme.

Similarly, in dislocated phrases like J'en ai un sot, éléphant 'I have a silly one, an elephant' the final [t] is realized as the onset to the dislocated noun and the vowel is tense, as in the citation masculine. (I gather this is so even for normative speakers who might be inclined to say, without dislocation, [sOt] éléphant.) This too follows from the constraint in (26). The function of Lex( $]_{\mathrm{AP}}$, gender) is - like that of all LexPM conditions - to the manipulate similarity to known forms in facilitating the interpretation of unfamiliar, non-lexicalized expressions.

It is clear however, from data like (27), that this condition will not always prevail:

(27) a. J'en ai un bel, éléphant 'I have a beautiful one, elephant' [bEl. \$ e.le.fA)], *[be. \$ le.le.fA)], *[bo.\$ e.lefA)], *[bo \$ le.le.fA)]

b. J'en ai un vieil, éléphant 'I have an old one, elephant' [vjEj. \$ e.le.fA)], ${ }^{*}\left[v j E\right.$. \$ je.le.fA)], ${ }^{*}\left[v j P . \$\right.$ e.lefA)], ${ }^{*}[v j P . \$$ je.lefA)]

In these phrases the constraint Lex ( $]_{\mathrm{AP}}$, gender) is being violated: the forms $[\mathrm{bEl}]$ and $[\mathrm{vjEj}]$, which contain the right edge of the AP are not identical to a listed masculine form of either adjective. We note that the impossible *[bo $\$$ e.le.fA)], which does satisfy Lex (] AP, gender) involves a violation of Lex P- $\forall$ loose: the liaison $\mathrm{VC}$ sequence [ol] is not even loosely similar to anything found in the paradigm of $[\mathrm{bo}] /[\mathrm{bEl}]$. Further, we will assume that the pronunciation of phrases like those in (27) is in part the effect of ranking *Hiatus > Lex (] AP, gender): this will exclude the option [bo] \$ éléphant . But this is still insufficient to fully predict the correct syllabification of the dislocated phrase, because it does not differentiate the option *[bE. \$ le.le.fA)] from the correct [bEl. \$ e.le.fA)], as seen below. 
(28) listed allomorphs: [bo], [bEl]

\begin{tabular}{|l|l|l|l|}
\hline & $*$ Hiatus & LexP- $\forall$ loose & Lex ] \\
\hline i. $+[\mathrm{bEl}]$, gendéphant & & & $*$ \\
\hline ii. $[\mathrm{bE}]$ \$ l-éléphant & & & $*$ \\
\hline iii. [bo] \$ éléphant & $* !$ & & \\
\hline iv. [bo] \$ 1-éléphant & & $* !$ & \\
\hline
\end{tabular}

To differentiate the top two candidates in (28) we suggest a further LexP constraint, which requires that the right edge of the AP be identical to the right edge of some listed allomorph of its last morpheme: note that the correct syllabification, [bEl. \$ e.le.fA)], aligns the right edge of the AP to [bEl], identifiable as an existing allomorph of the relevant adjective. In contrast, [bE], of *[bE. \$ le.le.fA)], ends the AP with a string that cannot be traced to any lexical entry.

(29) Lex A-phrase: For any $\mu$, if $\mu$ is the last morpheme in an AP then the right edge of the AP is identical to the right edge of some listed allomorph of $\mu$,

Regardless of its ranking, this constraint will succeed in differentiating *[bE. \$ le.le.fA)] from [bEl. \$ e.le.fA)].

\section{Implications and conclusions}

The analysis presented here has broader implications for correspondence theory, beyond the issue of lexical conservatism. It documents the need for global correspondence conditions, such as the English Lex $\sigma$ ! and the French Lex P- $\forall$. The edge-of-AP conditions motivated in the last section fall into the same category. Once global correspondence conditions are adopted, it becomes necessary to recognize that they come in different degrees of strictness. It will perhaps be possible now to experiment with the idea that rankings among correspondence constraints of the same type (Lex P or Lex PM) are, to a large extent, fixed, in the way in which the strict and loose versions of Lex P- $\forall$ are predictably ranked in French.

The clearest conclusion of the study is that entire paradigms of lexically related forms participate in computing the phonological properties of novel expressions. Some listed members participate by lending phonologically desirable properties to the novel expression; these members function as phonological bases. Thus remédial is a phonological base for remédiable, because its contribution in the creation of the latter is to legitimize its optimal stress pattern. Similarly, the feminine 
$[\mathrm{bEl}]$ is a phonological base in the formation of the masculine NP [bEl elefA)]: its use is to justify the use of the hiatus breaking [1]. Other listed members function to insure the presence in the novel expresson of required morphosyntactic or semantic properties. Thus the existence of the verb rémedy is a necessary condition for the formation of the remédiable: no productive -able forms are based on paradigms lacking a verbal member. This establishes the fact that, in addition to its phonological base remédial, the adjective remédiable possesses a distinct morphosyntactic base. In the case of French masculine liaison, the morphosyntactic base - the masculine citation form - plays a direct role in computing the phonology of liaison phrases: it accounts for the vowel quality in non-normative cases like [sot] $a m i$, it explains for the quality of the last $\mathrm{C}$ in cases like [fOÂ] accent and it dictates syllabification in dislocated phrases like masculine [pti.telefA)] vs. feminine [ptit.elefA)t]. Thus neither the feminine nor the masculine can be identified as the unique reference term in the formation of any of these expressions. We conclude that no unique expression functions as THE base in the formation of either words or phrases. The base is the paradigm.

\section{REFERENCES}

Aronoff, Mark.1976.Word Formation in Generative Grammar. Cambridge: MIT Press.

Benua, L. 1995. "Identity Effects in Morphological truncation". Papers in Optimality Theory ed. by J. N.Beckman, L.W. Dickey and S. Urbanczyk, 77136, University of Massachusetts Occasional Papers, 18.Amherst: GLSA

Burzio, L. 1994.Principles of English Stress, Cambridge: Cambridge University Press.

Burzio, L. 1997. "Multiple Correspondence". Paper presented at LSRL 27, 1997.

Cutler, A. 1989. "Auditory lexical access: where do we start?". Lexical

Representation and Process ed. by W.Marslen-Wilson, 342-356, Cambridge: MIT Press.

Delattre, P. 1966. Studies in French and Comparative Phonetics. The Hague: Mouton.

Dell, F. 1974. Les Règles et les Sons. Paris: Hermann.

Dell, F. 1984. "L'accentuation des phrases en français". Forme Sonore du Langage ed. by F.Dell, D.Hirst and J.-R. Vergnaud. Paris: Hermann.

Flemming, E. 1995. Auditory features in Phonology . UCLA Ph.D.Dissertation Fouché, P. 1959.Traité de prononciation française. Paris: Klincksieck. 
Halle, Morris. 1973. "Prolegomena to a theory of word formation". Linguistic Inquiry 4.3-16.

Hayes, B. 1981 [1985] A Metrical Theory of Stress Rules, PhD dissertation, MIT. (published 1985 by Garland Press, NY).

Kawasaki, H. 1986. "Phonetic Explanation for Phonological Universals: The Case of Distinctive Vowel Nasalization".Experimental Phonology ed. by J.Ohala and J.Jaeger. San Diego:Academic Press.

Kenstowicz, M. 1996. "Base Identity and Uniform Exponence". Current Trends in Phonology, ed. by J.Durand and B.Laks. Paris X and University of Salford.

Liberman, M. and A. Prince. 1977. "On stress and linguistic rhythm". Linguistic Inquiry, 8.249-336.

Marslen-Wilson, W. 1989. "Access and Integration". Lexical Representation and Process ed. by W. Marslen-Wilson, 3-24. Cambridge: MIT Press.

McCarthy, J. and A.Prince.1995. "Faithfulness and Reduplicative Identity". University of Massachusetts Occasional Papares in Linguistics 18: Papers in Optimality Theory ed. by J. Beckman, L. W.Dickey and S. Urbanczyk. Amherst: GLSA.

Morin, Y-C. 1992. "Un cas méconnu de la déclinaison de l'adjéctif français; les formes de liaison de l'adjéctif antéposé."Le mot, les mots, les bons mots ed. by André Clas. Montréal: Les Presses de l'Université de Montréal.

Ohala, J. 1981. "The listener as a source of sound change". Papers from the parasession on language and behavior ed. by C. Masek, R. Hendrick and M. F. Miller, 178-203. Chicago: Chicago Linguistic Society

Perlmutter, D. 1996. "Interfaces: Explanations of Allomorphy and the Architecture of Grammars". Morphology and its Relation to Syntax and Phonology ed. by S. Lapointe, D. Brentari and P. Farrell. Stanford: CSLI Publications.

Prince, A. 1983. "Relating to the Grid". Linguistic Inquiry. 14. 19-100.

Prince, A. and P.Smolensky. 1983. Optimality Theory. Ms. Rutgers University and University of Colorado.

Prunet,J.-F. 1987. "Liaison and nasalization in French". Studies in Romance Languages ed. by C.Neidle and F.Nuñez-Cedeño. Dordrecht: Foris.

Steriade, D. 1996 "Paradigm Uniformity and the Phonetics-Phonology Boundary". Paper presented at the 5th Conference in Laboratory Phonology, Northwestern University. To appear in proceedings.

Steriade, D. 1998. "Lexical conservatism and the Notion Base of Affixation". Paper presented at LSA meeting, NY and Current Trends in Phonology II, Royaumont.

Tranel, B. 1981. Concreteness in Generative Phonology: Evidence from French.. Berkeley and Los Angeles: The University of California Press. 


\section{Donca Steriade}

Tranel, B. 1987. The Sounds of French: An Introduction..Cambridge and New York: Cambridge University Press.

Tranel, B. 1990. "On suppletion and French liaison". Probus . 2.169-208

Tranel, B. 1996. "Suppletion and OT: On the Issue of Syntax/Phonology Interaction". WCCFL 16. 